IZA DP No. 9853

What You Don't Know... Can't Hurt You?

A Field Experiment on Relative Performance Feedback in Higher Education

Ghazala Azmat

Manuel Bagues

Antonio Cabrales

Nagore Iriberri

March 2016 


\title{
What You Don't Know... Can't Hurt You? A Field Experiment on Relative Performance Feedback in Higher Education
}

\author{
Ghazala Azmat \\ Queen Mary University of London and IZA
}

Manuel Bagues

Aalto University and IZA

Antonio Cabrales

University College London

Nagore Iriberri

University of the Basque Country and IKERBASQUE

\author{
Discussion Paper No. 9853 \\ March 2016
}

\author{
IZA \\ P.O. Box 7240 \\ 53072 Bonn \\ Germany \\ Phone: +49-228-3894-0 \\ Fax: +49-228-3894-180 \\ E-mail: iza@iza.org
}

\begin{abstract}
Any opinions expressed here are those of the author(s) and not those of IZA. Research published in this series may include views on policy, but the institute itself takes no institutional policy positions. The IZA research network is committed to the IZA Guiding Principles of Research Integrity.

The Institute for the Study of Labor (IZA) in Bonn is a local and virtual international research center and a place of communication between science, politics and business. IZA is an independent nonprofit organization supported by Deutsche Post Foundation. The center is associated with the University of Bonn and offers a stimulating research environment through its international network, workshops and conferences, data service, project support, research visits and doctoral program. IZA engages in (i) original and internationally competitive research in all fields of labor economics, (ii) development of policy concepts, and (iii) dissemination of research results and concepts to the interested public.
\end{abstract}

IZA Discussion Papers often represent preliminary work and are circulated to encourage discussion. Citation of such a paper should account for its provisional character. A revised version may be available directly from the author. 


\section{ABSTRACT \\ What You Don't Know... Can't Hurt You? A Field Experiment on Relative Performance Feedback in Higher Education*}

This paper studies the effect of providing feedback to college students on their position in the grade distribution by using a randomized control experiment. This information was updated every six months during a three-year period. In the absence of treatment, students' underestimate their position in the grade distribution. The treatment significantly improves the students' self-assessment. We find that treated students experience a significant decrease in their educational performance, as measured by their accumulated GPA and number of exams passed, and a significant improvement in their self-reported satisfaction, as measured by survey responses obtained after information is provided but before students take their exams. Those effects, however, are short lived, as students catch up in subsequent periods. Moreover, the negative effect on performance is driven by those students who underestimate their position in the absence of feedback. Those students who overestimate initially their position, if anything, respond positively.

JEL Classification: J71, J44

Keywords: relative performance feedback, ranking, randomized field experiment, school performance

Corresponding author:

Manuel Bagues

Aalto University

Department of Economics

P.O. Box 21240

00076 Helsinki

Finland

E-mail: manuel.bagues@aalto.fi

\footnotetext{
* We would like to thank César Alonso, Brian Jacob, Imran Rasul, Javier Ruiz-Castillo, Natalia Zinovyeva and participants in presentations at Aalto University, Universidad Carlos III de Madrid, CSEF, East Anglia University, University of Essex, Institute of Fiscal Studies, London School of Economics, Norwegian School of Economics, Nagoya University, Universidad de Navarra, University of Oslo, Université de Paris I, Warwick University, Workshop on Experimental Economics at Granada, the Institute for Economic International Studies, Zurich University and Lancaster University for their useful comments. We also acknowledge the support of Isabel Gutiérrez and the administration of Universidad Carlos III for conducting this study. Manuel Bagues acknowledges financial support from Ministerio de Economía y Competición (ECO 2012-31358). Antonio Cabrales acknowledges financial support from Ministerio de Economía y Competición (ECO ECO2012-34581). Nagore Iriberri acknowledges financial support from Ministerio de Economía y Competición (ECO2012-31626), Departamento de Educación, Política Lingüística y Cultura del Gobierno Vasco (IT869-13). All remaining errors are our own.
} 


\section{Introduction}

Universities play a key role in the human capital accumulation process. Across the OECD, the average proportion of individuals aged between 25 and 34 with tertiary education increased from 26 percent in 2000 to nearly 40 percent in 2012. A natural consequence of an increase in the proportion of university-educated individuals is a reduction in the signaling value of a university degree (Spence, 1973). The university market has adapted to this change in various ways. In the US, for instance, the competition for admission to the most selective universities has increased (Hoxby, 2009). Moreover, university students react to the increase in the number of their peers by striving to perform well such that they can "stand out from the crowd" and improve their employment opportunities (Hoxby 2009).

In parallel with increased university entry, there has been increased competition between universities, given the greater propensity of students to exercise choice. Universities strive to improve or establish a good reputation to attract the best students and, quite often, to attract funding. One way in which reputation is measured is through rankings, which are nationally or internationally well-known. An important component of university rankings is student satisfaction: the National Student Survey (NSS) in the UK or American National Survey of Student Engagement (NSSE) in the US. Results from those surveys show that there is an increasing demand on universities to provide students with more feedback on their performance. Williams and Kane (2009), for example, show that "assessment and feedback routinely score less well than other course-related aspects of the student experience and have done so for many years."

Despite the importance of university education and its consequences, few studies have explored the technology of student performance. ${ }^{1}$ In this paper, using a randomized field experiment, we study the effect of providing relative performance feedback -namely, students' decile rank with respect to other students in their cohort- on sub-

\footnotetext{
${ }^{1}$ Existing studies have focused on aspects such class size (Bedard and Kuhn 2008), peer effects (Sacerdote 2001), class attendance (Crede, Roch and Kieszczynka 2010) and teaching methods (Emerson and Taylor 2004, or Gok 2011).
} 
sequent performance and student satisfaction. Upon the completion of their studies, students are often aware, or at least better informed, of how they compare to their classmates. However, large cohort sizes or a lack of transparency on grade information, often mean that students are unaware of their relative standings during the course of their studies. This information is, nonetheless, potentially relevant to the students for many of their choices within university. For instance, students might use the information to select courses or majors, determine how much effort to exert, or choose the type of employers or jobs to target. It is thus important to understand the effect of the provision of information on educational outcomes, namely, academic performance and student satisfaction, as well as the underlying mechanism.

We therefore conduct a randomized controlled trial over four years (2009-2013) in a large Spanish university to study the effect of providing relative performance feedback on educational outcomes. A cohort of approximately 1,000 students enrolled in various degrees were randomly assigned into treatment and control groups. Students in the control group, as per usual, received only information on their own performance. Students in the treatment group were additionally provided with access to information on their decile position in the distribution of performance of their cohort. Students undertake exams every six months, at the end of each semester. Relative performance feedback is provided to students in the treatment group for the first time at the end of the first semester of their second year of study and is updated every six months until the end of the fourth (and final) year of the degree. We follow students throughout their four year degree programs. An important aspect of our study is that we conduct an out-of-trial survey on students' prior beliefs, which allows us to understand the mechanism through which the treatment affects performance and satisfaction.

We find that the academic performance of students in the treatment and control groups in the pre-treatment year (first year of degree) is similar. Once the treated students are provided with their rank information, we observe a significant decrease in their performance relative to those in the control group. In particular, during their second year, treated students have a lower accumulated GPA (0.05 standard deviations 
of the mean). They also complete, on average, 0.4 fewer course modules than students in the control group (0.1 standard deviations of the mean). Thus, providing students with information on their relative position in the cohort has an immediate detrimental effect on their academic performance. An important advantage of our study is that, as we follow the students until the completion of their degree, we can look beyond the immediate impact of treatment and study the long-run effects of the provision of feedback. We find that the provision of feedback information has a short-lived effect on academic performance. In particular, we show that students whose performance deteriorated in response to the feedback information make up most of the difference in grades with respect to the control students relatively rapidly. At the end of the academic year, students are given the opportunity to retake failed exams. We find that after this period, treated students complete the same number of courses as students in the control group. Although the accumulated GPA is still lower at the end of the academic year, by the time students graduate, the performance of the treatment and control groups — as measured by the likelihood of graduating or the average accumulated GPA at end of the degree - is statistically indistinguishable. In the third year, when students have the opportunity to select different courses, we do not observe any difference across groups in the courses selected. In particular, the degree of difficulty of the courses chosen is the same in both groups.

We further investigate the impact of the intervention on student satisfaction. Each semester -before sitting for exams- students complete a survey on teaching satisfaction. In the pre-treatment period, we find that the treated and control students report similar levels of satisfaction. Interestingly, after the provision of feedback (for the first time) but before sitting for exams, treated students report a higher level of satisfaction. In the same survey, students self-report their effort (hours of study per week). There is no statistically significant difference in self-reported effort between students in the treated and control groups neither before nor after the treatment. This is at odds with the lower actual performance, as measured by students' grades. This suggests that although students feel that they are studying more, this is not reflected in how they 
actually perform.

To understand the mechanism that drives the effects of feedback on performance and satisfaction, we provide a theoretical framework to understand under which conditions the relative performance feedback will have a positive or a negative impact. In particular, we show that two issues are vital to understanding the sign of the effects of information provision. First, the type of objective functions that individuals maximize, in particular, whether they maximize only their own performance, or whether they also care about their relative standing in a competitive manner. Second and more important, we consider individuals' prior beliefs regarding their, and others', abilities, in particular, whether, in the absence of information, they were underestimating or overestimating their relative position. To be slightly more precise, in a context where individuals have competitive preferences, determining that one's ability, with respect to others', is higher than initially believed, when underestimating, leads to lower effort provision, and conversely, learning that one's relative ability is lower than initially believed, when overestimating, leads to greater exertion of effort.

To test our theoretical mechanism, we conduct student surveys on prior beliefs of their relative standing. The average student makes an error in her prediction of 22 percentiles, confirming that students are indeed unaware of their relative standing. Contrary to the commonly held belief that people are generally overconfident about their ability, it has been shown that over- and underconfidence vary systematically, and there tends to be underconfidence on difficult tasks (Moore and Cain, 2007). Similarly, in our study, the average student tends to underestimate her relative ranking by 18 percentiles. It is also likely that, as the university attracts the best students, the average student feels (or fears) that he or she is worse than his or her peers, which is why students underestimate their position in the ranking in the absence of information. Using these surveys, we are able to distinguish the effect on performance with respect to those students who initially underestimate or overestimate or to whom no news is conveyed regarding their relative position. For students who overestimate their position the provision of information leads, if anything, to an increase in performance. For those 
students who received no news given their prior beliefs, the effect is close to zero.

Our study relates to the empirical literature on the effect of relative performance feedback, both in educational and workplace settings. In an educational setting, Azmat and Iriberri (2010) show that the performance of high school students improved notably when, due to a change in the the school's IT system, the report card added information on the average grade obtained by students in the class. Similarly, Tran and Zeckhauser (2012) find that Vietnamese students increase their effort and perform better in an English course when provided with their rank. Katreniakova (2014) performs an experiment on the impact of feedback on relative performance in several Ugandan schools. The provision of feedback improves students' performance, particularly when financial or reputational rewards are also present. Unlike our study, these studies do not elicit information on students' beliefs concerning their relative position. Moreover, in contrast to our work, these studies focus on pre-tertiary education and only on short-term impacts. For a workplace setting, Blanes-i-Vidal and Nossol (2011) find that workers increase their effort after they begin to receive feedback on their relative performance, provided that their pay was related to output. Barankay (2011), in a three-year randomized control trial, shows that the provision of feedback has a negative effect on the performance of furniture salespeople. In his setting, unlike in ours, information is removed for the treated group, rather than provided. Initially, all salespeople regularly receive feedback on relative performance. The feedback is then stopped for a random (treated) group of the salespeople. A possible explanation for these mixed results might be that, as these studies do not account for individuals' beliefs prior to the provision of information, in different contexts agents may hold different priors regarding their relative performance or possibly different objective functions. Regarding the importance of the objective function, Blader, Gartenberg and Prat (2015) show that the objective function of the workers is relevant for the effect of information provision on outcomes. They show that the provision of feedback may have a negative or a positive effect on the performance of truck drivers, depending on whether they have undergone a program that was intended to develop a more team-oriented environment. 
In a lab setting, studies have investigated the role of feedback information under various conditions. Eriksson et al. (2009), in a real-effort experiment, find that while feedback does not affect performance, it increases the mistake rate of the worstperforming agent. Hannan, Krishnan and Newman (2009) and Azmat and Iriberri (2016) study the effect of feedback provision under different incentive schemes. Hannan et al. (2009) find that, while performance improves under piece-rate incentives, it decreases in a tournament setting and is unchanged under fixed-rate incentives. Similarly, Azmat and Iriberri (2016) find that performance improves under piece-rate and is unchanged under flat-rate incentives. They also find that the provision of feedback information increases inequality in satisfaction when performance is related to pay (piece rate) but not when it is independent of pay (flat rate). Under flat-rate incentives, Charness, Masclet and Villeval (2013) provide subjects with their rank in the session, and Gerhards and Siemer (2014) provide information regarding who the best performers are. They find that individuals choose higher effort when this information is privately and publicly provided. More recently, Gill et al. (2016) estimate the reaction function of effort to rank information under flat-rate incentives. None of these studies elicit beliefs on ranking position in the absence of information. On the contrary, Khunen and Tymula (2012), consistent with our results, find that the impact of feedback depends crucially on individuals' prior beliefs. Under flat-rate incentives, they find that those individuals who rank lower than expected increase effort and those who rank higher than expected reduce effort, although the overall effect is positive.

The results of our study show that, in an environment where there is growing pressure to provide more information, providing ranking information might have negative consequences. We highlight that heterogeneity in underlying preferences and beliefs plays a key role in the response to performance feedback. Moreover, these responses will be context dependent such that in some educational and labor market settings, individuals will display more competitive preferences toward others, while in other settings, they may only be concerned with their absolute performance. In the context of college education, which is the focus of this paper, although students are not explicitly 
rewarded based on their relative performance, a number of their later outcomes may directly or indirectly depend on relative ranking (for instance, internships and labor market opportunities). It is, therefore, reasonable to assume that students will have competitive preferences.

The paper is organized as follows. Section 2 presents the theoretical framework. Section 3 describes the institutional background and the design of the experiment, as well as the additional surveys we conducted in the field. Section 4 presents the data. Section 5 reports the empirical analysis, and finally, Section 6 concludes.

\section{Theoretical Framework}

From a theoretical perspective, the impact of relative performance feedback on effort is ambiguous. An agent's reaction depends on the agent's prior beliefs regarding own and others' ability, the new information inferred from the feedback, and on the agents' inherent motivations. For example, if ability is complementary to own effort for the purpose of achieving a particular outcome, positive (negative) news about own ability will make individuals work more (less). Moreover, agents might care about their relative standing, displaying a "competitive" motivation in their preferences, perhaps because corporate recruiters or graduate school admissions officers value relative in addition to absolute performance. If that is the case, learning that others' ability is lower (higher) than initially thought could make agents exert a lower (higher) level of effort.

We introduce a theoretical model that includes different drivers of motivation, and in which ability and effort are complements, to help interpret the possible reactions to the provision of relative performance feedback. We show that both the different motivations and the informativeness of the feedback relative to agents' prior beliefs, are crucial when predicting a particular direction in the change of effort.

Let the utility of an individual depend on her output, $F$, where output is a function of individual's effort $x_{i}$ and ability $\theta_{i}$ in a complementary fashion, and $0<\delta<1$ is a constant.

$$
F\left(x_{i}, \theta_{i}\right)=\left(\theta_{i} x_{i}\right)^{\delta}
$$


Given the complementarity between $x_{i}$ and $\theta_{i}$, the marginal output of effort $x_{i}$ is increasing in ability $\theta_{i}$ :

$$
\frac{\partial F\left(x_{i}, \theta_{i}\right)}{\partial x_{i} \partial \theta_{i}}=\delta^{2}\left(\theta_{i} x_{i}\right)^{\delta-1}>0
$$

Assume further that individuals have a "competitive" motivation in their preferences such that their utility also depends on their relative standing in the group. For example, the individuals are competing for a prize and the probability that individual $i$ wins the price is given by the expression

$$
G\left(x_{i}, \theta_{i}, x_{-i}, \theta_{-i}\right)=\left(1-e^{-\left(\theta_{i} x_{i}-\theta_{-i} x_{-i}\right)}\right)
$$

where clearly a higher talent $\theta_{i}$ or effort $x_{i}$ of individual $i$ makes it more likely that she wins the prize, while a higher talent $\theta_{-i}$ or effort $x_{-i}$ of opponents makes her winning less likely.

Note that own effort and others' effort are strategic complements in $G($.$) because$

$$
\frac{\partial G\left(x_{i}, \theta_{i}, x_{-i}, \theta_{-i}\right)}{\partial x_{i} \partial x_{-i}}=\theta_{i} \theta_{-i} e^{-\left(\theta_{i} x_{i}-\theta_{-i} x_{-i}\right)}>0
$$

and that marginal product of own effort $x_{i}$ in the competitive motivation function is increasing in the ability of others $\theta_{-i}$

$$
\frac{\partial G\left(x_{i}, \theta_{i}, x_{-i}, \theta_{-i}\right)}{\partial x_{i} \partial \theta_{-i}}=\theta_{i} x_{-i} e^{-\left(\theta_{i} x_{i}-\theta_{-i} x_{-i}\right)}>0
$$

but in terms of the competitive motivation, own effort $x_{i}$ and own ability $\theta_{i}$ may be complements or substitutes, as the sign of the derivative

$$
\frac{\partial G\left(x_{i}, \theta_{i}, x_{-i}, \theta_{-i}\right)}{\partial x_{i} \partial \theta_{i}}=\left(1-\theta_{i} x_{i}\right) e^{-\left(\theta_{i} x_{i}-\theta_{-i} x_{-i}\right)}
$$

depends on whether $\theta_{i} x_{i}$ is smaller or larger than 1 . 
Total utility is given by:

$$
\alpha F\left(x_{i}, \theta_{i}\right)+\beta G\left(x_{i}, \theta_{i}, x_{-i}, \theta_{-i}\right)-C\left(x_{i}\right)
$$

Relative performance feedback can be informative about own and others' ability.

Assume first that relative performance feedback informs the decision maker that others' ability $\theta_{-i}$ is lower than expected and thus that she was underestimating her relative position. Then, the reaction function for the effort of agent $x_{i}\left(\theta_{i}, x_{-i}, \theta_{-i}\right)$ will shift down from the effect on the competitive motivation (eq. 4). Moreover, if everyone lowers their estimate of the ability of opponents, given the strategic complementarity between own effort and others' efforts (from eq. 4), then the equilibrium effort $x_{i}^{*}$ will decrease for everyone.

Assume next that relative performance feedback reveals that own ability $\theta_{i}$ is higher than initially thought. Then the effect is more complicated. On the one hand, from the complementarity of own effort and ability in $F($.$) , the reaction function for effort$ should shift up (see eq. 1), but because the relationship between own ability and effort in the competitive motivation $G($.$) could be one of substitutability, the reaction$ function for effort could shift down (if $\theta_{i} x_{i}>1$, see eq. 5). Then, if the shift in the reaction function is the same for everyone (up or down depending on the relative sizes and signs of effects on $F($.$) or G()$.$) , the strategic complementarity of own and$ others' efforts should shift the equilibrium choice of effort for everyone in the same direction, up or down, as in the individual reaction functions. People with a high relative desire for maximizing their own output versus having a high standing within the cohort $(\alpha>>\beta)$ could increase effort after learning that their relative position is better than expected, whereas people with a high relative desire for having a high standing within the cohort versus maximizing their own output $(\beta>>\alpha)$ and a value for $\theta_{i} x_{i}>1$ (such that own effort $x_{i}$ and own ability $\theta_{i}$ are substitutes in $G($.$) ) could$ decrease effort after learning that their relative position is better than expected.

The final effect therefore depends on the prior knowledge of own ability $\theta_{i}$, versus the knowledge of others ability $\theta_{-i}$. If information concerning $\theta_{-i}$ is the only novelty, the 
effect would be an unambiguous decrease in effort, provided that $\beta>0$. If information regarding $\theta_{i}$ is the novelty, then the effect would be ambiguous.

This theoretical framework demonstrates that different motivations in utility, the expectations individuals have prior to the provision of information, and whether feedback is informative of own ability or others' ability are important determinants of effort choices, which can lead to different reactions in effort. Note, however, that the fact that the framework allows for different responses does not mean that the model does not provide guidance as to what effects we should find. Particular directions for the effect depend on particular types of information. For example, it is natural to expect that knowledge of own ability $\theta_{i}$ is more precise than knowledge of others ability $\theta_{-i}$, particularly in a university, where all peers are relatively new for most students. Therefore, the feedback will make individuals update their knowledge of others' ability rather than their knowledge of their own ability.

In terms of motivations it seems likely that students have strong competitive motives. Grades in a university serve as a signal of ability to potential employers and to graduate school admissions officers. This means that although some students will have an intrinsic motivation to have better grades, it is likely that many of them will have an even stronger desire to perform well with respect to others. If this is the case, the dominant force will be the one that shifts effort up or down in the presence of a negative or positive surprise.

\section{Background and experimental design}

We conducted a randomized control trial over four years (2009-2013) at University Carlos III in Madrid, Spain. The university offers several four-year and six-year degrees on three different campuses. The majority of students pursue their degree in Spanish, but a small minority do so in English. Our study involves students enrolled in the Spanish track of four of these four-year degrees - Business, Economics, Finance, and 
Law - and one six-year degree - Business and Law. ${ }^{2}$ Two of these degrees, Business and Business and Law, are held simultaneously in two different locations, the Northern and the Southern campuses. The study, therefore, involves students in seven different degree locations.

In the control group students receive information on their own performance (as is the norm). In the treatment group, students also receive information on their relative performance. We examine how the treatment affects students' educational performance and their satisfaction. Below we explain the most relevant features of this university and the design of the experiment.

\subsection{Educational Institution}

In Spain, access to university degrees is based on applicants' entry grade, which is calculated as a weighted average of their high school accumulated GPA (60\%) and the grade obtained on a standardized exam known in Spanish as Selectividad (40\%). University Carlos III offers the most selective degrees in the region according to the required minimum entry grade. ${ }^{3}$

An academic year includes two 14 -week terms. The first term takes place from September to December, with exams taken in January. The second term takes place from February to April, with exams taken in May. Students that fail to pass an exam on either of the two terms have the opportunity to retake that exam in June.

Each week students attend one lecture and one tutorial. The assignment of students to lecture and tutorial groups is based on the first letter of their surname. ${ }^{4}$ As an illustration, Figure 1 depicts how students enrolled in 2010 in the 1st year of the Business degree at the Southern campus were distributed across groups. For instance, students whose surname initial began with "A" or "B" were assigned to tutorial group

\footnotetext{
${ }^{2}$ The choice of degrees and campuses was based on data availability and size. We did not consider degrees for which there is only one lecture group.

${ }^{3}$ Information on minimum entry grades is available at http://portal.uc3m.es/portal/ page/portal/acceso_universidad/notas_corte_pc/notas_corte_09_10/notasmadrids09.pdf, retrieved on April 302015.

${ }^{4}$ The only exception are second-year students in the English track. This is why we do not consider these students in our analysis and restrict our attention to students in the Spanish track.
} 
number 74 and lecture group "74-75-76" (which combines tutorial groups 74, 75 and 76). In the Spanish context, surname order is uncorrelated with socio-economic status or academic performance, and as a result, performance across groups tends to be balanced.

All courses in the 1st and 2nd year of the degree are compulsory. Courses in the 3rd and 4th year of the degree tend to be optional. In each course, the final grade is usually a weighted average of the grade obtained in the end of term exams (60\%), midterm evaluations (20\%) and group presentations/assignments $(20 \%)$. The end of term exam is usually the same for different groups in the same subject.

Students' permanence at the university is subject to certain requirements. During their first year at Carlos III, students must pass at least two courses. By the end of their second year, they must have passed every first-year course. Finally, they cannot fail the same exam more than three times. If any of these conditions is not satisfied, students cannot pursue their studies. ${ }^{5}$

Students regularly receive information on the grades that they have obtained in each subject. The university summarizes this information through an official measure of accumulated grade point average (AGPA), which students can also access at any point in time on the university intranet. ${ }^{6}$ Students do not receive information on their position in the distribution of AGPAs, relative to other students, or about the AGPA of any other student.

Students are not explicitly rewarded for their relative performance, except for a prize given to the best student in the cohort. ${ }^{7}$ Nonetheless, relative performance might be relevant. For instance, many students enroll in the Erasmus exchange program, typically during their third or fourth year. Whether students are admitted to the

\footnotetext{
${ }^{5}$ More detailed information is available on the university's webpage http://portal.uc3m.es/ portal/page/portal/conocenos/nuestros_estudios/normativa_09/Permanencia), retrieved on February 112015.

${ }^{6}$ The university calculates the accumulated grade point average summing the grades obtained by the student, modified with a penalty for the number of times an exam is taken, and dividing this sum by the total number of courses taken. There is no penalty if the exam for the course is taken only once. If the student failed once, the course grade is multiplied by 0.95 , by 0.90 if the student failed twice, and so forth.

${ }^{7}$ This prize, known as premio extraordinario, is awarded by the Ministry of Education upon graduation.
} 
program is based on their performance in a language exam and their position in the grade distribution. The relative position of students in the grade distribution might also play a role when students apply for an internship, typically during the last year of the degree, or later after graduation, when they enter the labor market.

\subsection{Experimental Design}

The intervention was restricted to students who had entered the university in Fall 2009 and who were registered in at least one second-year course in Fall 2010. This condition excludes approximately 10 percent of the 2009 cohort, generally students who were expelled because they did not manage to satisfy one of the permanence requirements: passing at least two courses during the first year.

Students' were assigned randomly to the treatment or to the control group based on the lecture group in which they were enrolled. ${ }^{8}$ We selected randomly one of the 432 different possible assignments. The set of possible assignments was subject to the constraint that there be one treated group per degree location. As a result of the random draw, 623 students were assigned to the treatment group and 354 to the control group. Table 1 reports the distribution of students in the control and the treatment groups by degree and campus.

The intervention began in early December of 2010 and concluded three years later, at the end of the fourth academic year. During this period students in the treatment group were granted access to feedback on their relative performance every six months. Specifically, treated students received every six months an email message from a corporate account stating the following:

\footnotetext{
${ }^{8} \mathrm{~A}$ few students were enrolled in several groups. They were assigned to the group where they attended the majority of their courses.
} 


This email is part of a pilot project of academic assessment
management. If you want to see your average grade, and
your relative position in terms of average grade among the
students that started the degree the same year you did,
you can do it by clicking here

After logging in with their university login and password, students obtain access to a screen that displays their own AGPA and their position in the distribution of grades, measured in deciles (Figure 2).

We also collected information from three different surveys: (i) teaching evaluations completed by students, which are collected by the university (ii) a survey on students' knowledge of their relative position in the distribution of grades, administered to a sample of 2nd year students, who were not affected by the intervention, and (iii) a similar survey administered to a sample of graduating students belonging both to the treatment and the control groups. On the one hand, teaching evaluations will be useful because they provide measures of student satisfaction and their self-reported effort. On the other hand, the surveys on students' knowledge of their relative performance will be useful for measuring students' prior knowledge of their relative standing, both prior to and after the treatment.

\section{Baseline characteristics and balance check}

\subsection{Individual characteristics}

Table 2 provides information on the individual predetermined characteristics of the 977 students who participated in the intervention. Just over half of the students are women, and nearly all of them are Spanish. In general they previously attended high school, and only 5 percent have a vocational training background. Approximately two-thirds of the students come from the Madrid region, and within this region, most come from the center of Madrid (31 percent). Approximately 22 percent come from municipalities located in the southern part of the region, an area that tends to be less affluent. 
Students experience a significant decrease in their grades during their first year in university relative to the grades that they obtained in secondary education. While the average entry grade into the university is 7.24 (out of 10), the average AGPA at the end of the first year is equal to 6.02 , which implies a decrease of roughly one standard deviation. As shown in Figure 3, grades shift down along the entire distribution.

The average student in our sample is placed in percentile 54, relative to all students who also registered in the same degree the previous year. This figure is slightly higher than 50, reflecting that approximately 10 percent of first-year students failed to satisfy the permanence requirements.

We formally test whether these predetermined characteristics are balanced across the treatment and control groups using the following regression:

$$
X_{s, d, g}=\alpha+\beta \text { Treatment }_{d, g}+\boldsymbol{Z}_{\boldsymbol{d}} \boldsymbol{\lambda}+\epsilon_{s, d, g}
$$

where $X_{s, d, g}$ refers to a given predetermined characteristic of student $s$, enrolled in degree $d$ and tutorial group $g$. Treatment $t_{d, g}$ takes value one if the student is exposed to the treatment and the equation also includes a set of degree fixed effects $\left(Z_{d}\right)$. As expected, the two groups are very similar in terms of their demographic characteristics and their academic performance before the intervention took place. Of 14 observable characteristics, in no dimension is the difference significant at the $5 \%$, and in two dimensions the difference is significant at 10\% (Table 2, column 4). An F-test confirms that it is not possible to statistically reject that the assignment was random.

\section{$4.2 \quad$ Teaching evaluations}

Students were relatively satisfied with the quality of the courses they received before the intervention took place (Table 3, upper panel). ${ }^{9}$ On a scale from 1 (not at all) to 5 (very satisfied), students' average assessment is equal to 3.8. They are slightly

\footnotetext{
${ }^{9}$ Teaching evaluations are collected by the university administration twice per year. During academic year 2010-2011, students completed their 1st term teaching evaluations before the intervention took place, in late November, and they completed their 2nd term teaching evaluations after they had received feedback on their relative performance but before they had received the results of their second-term exams.
} 
less satisfied with the fairness of grading; again using a scale from 1 to 5 , the response answer is 3.6. The teaching evaluations also provide (self-reported) information on study time. Students devote between approximately 4 and 7 study hours to each subject in each week. ${ }^{10}$ Taking into account that there are typically 5 or 6 courses per term, this implies that on average students spend approximately 32 hours studying each week, which combined with class attendance, implies that the average student devotes approximately 50 hours per week to college-related work. ${ }^{11}$

We verify whether the treatment and the control groups were similar on these dimensions before the intervention took place using the following regression: ${ }^{12}$

$$
Y_{c, g, d}=\alpha+\beta \text { Treatment }_{c, g, d}+\boldsymbol{X}_{\boldsymbol{c}} \boldsymbol{\gamma}+\boldsymbol{Z}_{\boldsymbol{d}} \boldsymbol{\lambda}+\epsilon_{c, g, d}
$$

where $Y_{c, g, d}$ represents some average self-reported measure in course $c$ (e.g. Econometrics I), tutorial group $g$ (e.g. group 72) and degree $d$ (e.g. Business at the Southern Campus). The regression includes a set of course fixed effects $\left(\boldsymbol{X}_{\boldsymbol{c}}\right)$ and degree fixed effects $\left(\boldsymbol{Z}_{\boldsymbol{c}}\right)$.

As shown in columns 3 and 4, students in the treatment and control groups report very similar values before the intervention in terms of their overall satisfaction with courses, the fairness of the grading and the hours of study.

\footnotetext{
${ }^{10}$ This information is only available at the group level. Hours of study takes value 1 if the individual studied less than one hour per week; value 2 for between one and four hours of studying; value 3 for four to seven hours of studying; value 4 for seven to ten hours of studying; and value 5 for more than ten hours of studying.

${ }^{11}$ According to survey information provided by teachers, the attendance rate at lectures is approximately $80 \%$ (Information available at https://portal.uc3m.es/portal/page/portal/calidad/ Resultados_encuestas_a_alumnos_y_profesores/00_Informe_1_cuatrimestre_2012_2013.pdf, retrieved on April 30, 2015). Each course includes four hours of weekly lectures, which implies that a student enrolled in 5.5 courses who attended $80 \%$ of lectures would spend 18 hours weekly in class.

${ }^{12}$ Teaching evaluations are anonymous, and hence we cannot match the teaching evaluations to the students in our sample. However, as we know the tutorial group to which the teaching evaluations belong, we can assign teaching evaluations to the treatment and the control group based on the tutorial group during academic year 2010-2011, when students were registered in compulsory 2nd year courses. Unfortunately we cannot match the information during the third and the fourth academic years, when most courses are elective.
} 


\subsection{Students' prior information on relative performance}

The intervention provides treated students with information on their position in the grade distribution at the beginning of their second year. The impact of this treatment depends crucially on the information that was available to students before the intervention. We investigate students' knowledge about their position in the grade distribution, absent of any intervention, using information from another cohort of students. We conducted a survey among a group of students from the 2010 cohort at the beginning of their second year (November 2011). The survey was administered during the lecture of a compulsory course and in total 57 Economics students participated. ${ }^{13}$ We decided not to conduct this survey among students belonging to the treated cohort (2009 cohort) to avoid the introduction of any confounding effects that might affect their subsequent performance.

Students were asked to answer privately the following question: ${ }^{14}$

When you enrolled in this degree one year ago, your cohort
included $N$ students. If we were to rank all students in this
cohort by their accumulated grade point average (AGPA)
such that number 1 is the student with the highest AGPA
and number $N$ is the student with the lowest AGPA, in
which position do you think you would be?

The answers are reported in Figure 4. The $x$-axis reports the actual position of the student in the ranking, normalized between 0 (lowest grade) and 1 (highest grade) among students who enrolled in Economics in Fall 2009. The $y$-axis provides information on their self-reported relative performance, normalized in a similar way. Most observations lie far below the diagonal, reflecting that students tend to be uninformed. Moreover, students underestimate their position in the distribution of grades. The

\footnotetext{
${ }^{13}$ Specifically, we surveyed students enrolled in Game Theory, Degree in Economics, groups 63, 64, 68, and 69. A total of 21 people did not attend lecture on the day of the survey. All attending students except one participated in the survey.

${ }^{14} N$ was equal to 300 , which corresponds to the number of students who enrolled in 2010 in the Economics degree offered by Universidad Carlos III at its Southern Campus
} 
average student makes an error in her prediction of 22 percentiles and tends to underestimate her relative ranking by 18 percentiles. One possible explanation for this systematic divergence is that students may not have realized that the sharp decline in grades that they experienced during their first year in university affects all students, not only themselves.

To obtain a better understanding of which students underestimate their position in the distribution and which ones overestimate it, we estimate the following equation:

$$
Y_{s}=\alpha+\boldsymbol{X}_{\boldsymbol{s}} \beta+\epsilon_{s}
$$

where $Y_{s}$ refers to the difference between the self-reported and the actual relative ranking. The dependent variable takes positive values when students overestimate their own ranking and negative otherwise. The set of independent variables $\boldsymbol{X}_{\boldsymbol{s}}$ includes gender, entry grade, and performance during the 1st year. As shown in Table 4, underestimation is relatively stronger among women, among students with low high school grades, and among students who managed to receive relatively higher grades during their first in university. These observable characteristics explain approximately 50 percent of the variation in the gap between students' self-reported ranking and their actual position. Overall, this analysis shows that there is room for students to learn about their relative ranking and that the provision of feedback should indeed affect students' underestimation.

\section{Empirical analysis}

We analyze the impact of the intervention in different steps. First, we verify whether treated students actually accessed the link that they received by email. Second, we examine whether the intervention had a long-lasting differential impact on the information available to students in the treatment and control groups. Third, we study the impact on students' performance. Fourth, we study the effect on students' satisfaction. Finally, we discuss some robustness checks. 


\subsection{Do students access the information?}

The treatment consists of the possibility of obtaining information regarding their relative ranking, as students in the treatment group receive an email with a link to a personalized webpage where they can find feedback on their relative performance. As part of the design, we can observe whether students indeed accessed to the information and the number of times they did so. 72 percent checked this information at least once. The average student checked the ranking four times during the duration of the treatment. As shown in Figure 5, the probability of checking is strongly correlated with the position in the ranking. In the top quartile nearly 90 percent of students accessed the information, in the bottom quartile less than half did. Female students are also slightly more likely to check, but the difference is only marginally significant once we account for the ranking (Table 5).

Unfortunately, we cannot determine why some students do not check the information. Some individuals might not read emails from corporate accounts, while others perhaps read the email but prefer not to learn about their position in the ranking. One-third of the students that did not check their ranking were expelled from the university at the end of their second year due to their failure to meet the permanence requirements. It is possible that these students were not active students at the time of the intervention.

\subsection{Learning and information spillovers}

The intervention was designed to minimize information spillovers, but it is still possible that students from the control group received some information from treated students. Students in both groups might also increase their knowledge of their position in the distribution over time, independent of the intervention.

To study this issue, we surveyed a sample of students from the treatment and the control groups three years after the intervention concerning their relative ranking. The survey was conducted at end of the undergraduate thesis presentation, which is 
the final requirement that students satisfy before graduation. ${ }^{15}$ The sample includes 97 students from Economics, Business and Finance degrees. Four students did not reply to the survey. By construction, the sample of students surveyed is not a random sample of all students. Students in the upper part of the grade distribution are over-represented.

The information displayed in Figure 7 reveals two interesting patterns. First, compared with students at the beginning of their 2nd year, at the end of their 4th year students have more accurate information on their relative performance. The average error decreased from 22 percentiles to 12 percentiles. Second, students in the treatment group are significantly better informed than students in the control group. The average error is equal to 9 percentiles among students in the treatment group and to 15 percentiles among students in the control group (Table 6).

For students in the control group, this improvement might potentially reflect learning over time or potential information spillovers. Unfortunately we cannot disentangle these two hypotheses. Note also that students in the treatment group do not perfectly predict their position in the ranking. This might be due to several factors. First, students were asked about their exact position in the ranking, while the intervention provided access only to their position in terms of decile. Second, the survey was conducted after the final exams but before students could access information on their final ranking; the last update of the ranking information took place shortly after we conducted the survey. Third, a few students in this group (less than 10\%) had never checked the information provided. Finally, some students may have forgotten their position in the ranking.

Overall, we find that students, even in the absence of any intervention, improve their knowledge about their relative ranking. However, more important, we observe that the intervention affected students' knowledge of their ranking, decreasing the gap between their expected and true position in the ranking.

\footnotetext{
${ }^{15}$ To prevent (treated) students from having access to the information provided, they were not allowed to access the internet during the survey.
} 


\subsection{Feedback effect on academic performance}

We estimate the impact of feedback on academic performance. We compare the performance of all individuals in the treatment and the control groups (intention-to-treat effect), and we also report estimates from an instrumental variables (IV) estimation, where we instrument access to the feedback information using the random assignment to the treatment group.

\subsubsection{Intention-to-treat effect}

Table 7 provides information on students' academic performance during the three years of the intervention. The intervention took place in the fall of the second year. During the regular exam period of their second year, students take on average eleven exams and pass approximately eight. In June, students have the opportunity to retake exams that they have failed. During the second year reexamination period, students, take, on average, approximately three exams and pass one of them. The number of exams taken and passed during the third and the fourth year is slightly lower. By September of their fourth year approximately half of the students in our sample managed to graduate and $15 \%$ had dropped out, typically during their second year. ${ }^{16}$

We compare the performance of the treatment and the control group using the following regression:

$$
Y_{s, d, g, t+i}=\alpha+\beta \text { Treatment }_{d, g}+\boldsymbol{Z}_{\boldsymbol{d}} \boldsymbol{\lambda}+\epsilon_{s, d, g, t+i}
$$

where $Y_{s, d, g, t+i}$ represents the performance of student $s$, enrolled in degree $d$ and tutorial group $g$, in the academic term $t+i$, and $t$ refers to the time of the intervention. Treatment $_{d, g}$ takes value one if the student is exposed to the treatment, and the equation also includes a set of degree fixed effects $\left(\boldsymbol{Z}_{\boldsymbol{d}}\right)$. To account for the potential existence of common shocks, we report standard errors clustered at the tutorial group level (45 groups). In columns 3 and 4 of Table 7, we report the estimates from equation

\footnotetext{
${ }^{16}$ This calculation excludes 200 students who were enrolled in the Business and Law degree, which is six years long.
} 
(9), and in columns 5 and 6 we report results from a specification that also includes the set of predetermined individual characteristics $\boldsymbol{X}_{\boldsymbol{s}, \boldsymbol{d}, \boldsymbol{g}, \boldsymbol{t}}$ listed in subsection 4.1. As expected, the latter estimates are statistically similar but are slightly more precise.

We do not observe any impact on the number of exams taken by students during the regular exam period that year. However, the performance of the treatment group is significantly worse. On average, students in the treatment group passed 0.36 (9 percent of a standard deviation) fewer exams during the regular exam period, a difference that is significant at the 5 percent level. Rows 3 and 4 provide information about resits, which are scheduled in June. Students in the treatment group take 0.34 more retests, reflecting their higher failure rate during the year, and they manage to recover half of the gap. During the third and the fourth years, there are no significant differences in performance between the treatment and the control group. If anything, the performance of the treatment group is slightly better, and by the end of the fourth year, there are no significant differences between students in the treatment and control groups in terms of the number of exams passed, the dropout rate, time to graduation or the accumulated grade point average. In sum, the treatment group experiences a short-term negative impact on performance but in the longer term the gap disappears.

There are several possible explanations for why the treatment has a decreasing impact over time. The decreasing impact of the treatment over time may be partly related to the design of the intervention, which provides a relatively large amount of information in the first period but has decreasing informational content over time. An alternative explanation is that, as shown above, the control group tends to have more accurate information concerning their relative performance over time. Note that students receive information on their position in the ranking in terms of their AGPA. As, by construction, the influence of each additional course on their ranking decreases over time, students' position in the ranking varies increasingly less over time. As shown in Figure 6, while $45 \%$ of students experienced a variation in their ranking at the beginning of their 2 nd year, at the end of the 4 th year only 25 percent of students experience any such variation. 


\subsubsection{Instrumental variables}

Not all students in the treatment group accessed the information (Table 5). We also conduct the analysis using an instrumental variable (IV) strategy in which we use the (random) assignment to the treatment group as an instrument for accessing the information. The point estimates from the IV exercise are slightly larger, but overall, the results are statistically similar (Table 8).

The interpretation of these IV estimates depends on the mechanism that explains why some students in the treatment group did not access the ranking information. On the one hand, if those who did not access the information failed to do so because they did not receive or did not read the emails, then the IV estimates provide information on the average treatment effect on the treated. On the other hand, some students may have read the email but may have preferred not to obtain information on their relative performance. In this case, the treatment may have affected them even if they did not access the information, and the IV estimates would not have a straightforward interpretation.

\subsubsection{Effort}

The treatment negatively affected students' performance during the second year. In principle, this should reflect a decrease in their effort. However, we do not observe any significant impact on students' self-reported effort. We run equation (7) using students' self-reported effort as a dependent variable. As shown in the lower panel of Table 3, both the treated and control groups tend to report that they study between three and seven hours weekly per course. One possible explanation for this puzzling result is that perhaps the treatment was not strong enough to move students' effort beyond these boundaries.

\subsubsection{Heterogeneity analysis}

Are all students equally affected by the provision of information on relative performance? We consider several sources of heterogeneity. 
First, we consider the type of information that students received. We do not have direct information on the priors of students who participated in the intervention, but we can attempt to infer whether a given student was positively or negatively surprised by the feedback on relative performance by exploiting the information provided by the survey that was conducted during the second year among a group of students who were not affected by the treatment. We estimate the following equation:

$$
Y_{s}^{\text {self-reported }}=\alpha+\beta Y_{s}^{\text {true }}+\boldsymbol{X}_{s} \gamma+\epsilon_{s}
$$

where $\boldsymbol{X}_{\boldsymbol{s}}$ includes students' performance during their first year, gender and entry grade. We use these estimates to predict the type of news that students are expected to receive when they obtain access to the ranking information (see Table A1). We classify students into three groups, according to whether the actual ranking and the predicted ranking lie within the same decile (no news), the actual ranking is larger than the predicted one (positive news), or vice versa (negative news). Using this methodology we infer that 644 students are expected to underestimate their position in the distribution, 142 have an accurate estimate, and 180 overestimate it. Figure 8 depicts the distribution of these three groups according to the actual relative performance of students.

We regress equation (9) separately for these three groups of students, using as the dependent variable the number of exams passed during the second year during the regular exam period. According to our estimates, students who, according to our estimations, receive 'positive' news, pass 0.47 fewer exams during their second year, relative to comparable students in the control group. The treatment has virtually no effect on students who are expected to have correct priors regarding their position in the ranking. However, students receiving 'negative' news pass 0.26 more exams during their second year, although this effect is not statistically significant (Table 9, columns 2-4). Overall, these estimates are consistent with the hypothesis that the impact of information depends crucially on the students' priors.

Second, in columns 5-10, we examine the impact of the treatment according to 
the gender of students, their grades in high school and their performance during their first year in university. The impact is slightly larger in the case of women and students with low high school grades. We do not find any differential effect according to whether individuals are above or below the median during their first year in university.

\subsection{Satisfaction}

Providing feedback on relative performance has a short-term negative impact on the performance of students. This effect is driven by students who, according to their observable predetermined characteristics, are expected to receive positive news about their position in the distribution. To obtain a better understanding of the underlying mechanism, we investigate how the treatment affects students' satisfaction.

We cannot observe students' satisfaction at the individual level, but we can exploit the information provided by teaching evaluations. The satisfaction of the treated group is significantly higher than the satisfaction of the control group (approximately onethird of a standard deviation), suggesting that students' satisfaction increases when they learn that their relative performance is substantially better than expected (see the lower panel of Table 3).

\subsection{Robustness checks}

We consider two alternative ways in which the treatment may have affected students' performance: first, through changes in grading standards and, second, through, the choice of electives.

\subsubsection{Grading standards}

An alternative way in which grades can change is through changes in teachers' grading standards. In Carlos III University teachers do not explicitly grade on a curve, but nonetheless, we cannot discard the possibility that student performance affects grading standards in some manner. For instance, some teachers may unconsciously relax their grading standards if they realize that the overall performance of a certain group of 
students is relatively lower. This would introduce attenuation bias in our results. To investigate this issue, we compare the information provided by students through the teaching evaluations. After the intervention, both groups report statistically similar values in term of fairness of grading, indicating that students did not perceive any changes in grading practices (Table 3, lower panel).

A related problem would arise if the performance of the treatment groups affected the grading in the control groups, which would lead to a violation of the stable unit treatment value assumption (SUTVA). In this case, the observed gap in performance might overestimate the magnitude of the effect.

\subsubsection{Choice of electives}

During the third and fourth years, students can choose elective courses. A potential way to improve the relative position in the ranking would be to choose elective courses where grades tend to be higher. Students may enroll in courses with high grading standards or in courses where the value added provided is higher, also leading to higher grades.

To obtain a proxy for the grades that students may expect to obtain in each elective course, we collected information on the grades received by students in these courses during the two previous years. Overall, we observe 26,119 grades in 168 courses. Using this information, we estimate the following equation:

$$
\operatorname{Grade}_{c, s}=\alpha+\boldsymbol{C}_{\boldsymbol{c}} \boldsymbol{\beta}+\boldsymbol{S}_{\boldsymbol{s}} \boldsymbol{\gamma}+\epsilon_{c, s},
$$

where Grade $_{c, s}$ reflects the grade obtained by student $s$ in course $c$, and $\boldsymbol{C}_{\boldsymbol{c}}$ and $\boldsymbol{S}_{\boldsymbol{s}}$ are two vectors of course and individual dummies, respectively. The vector of coefficients $\boldsymbol{\beta}$ captures the average grade that students enrolled in each course obtain, conditional on their performance in other courses.

Using this information, we calculate the average grade associated with the elective courses chosen by students in the treatment and the control groups, and we normalized this variable to have mean zero and standard deviation one. We compare the choices 
of students in the treatment and the control groups using (9). Students in the treatment group tend to select elective courses with slightly higher grades (0.03 standard deviations), but the difference is not statistically significant (last row in Table 7).

\section{Conclusions}

In this paper, we study the role of relative performance feedback in a higher education setting, where there has been an increasing demand to provide students with more feedback on their performance. We elicit beliefs from students concerning their relative position and find that students in our study are uninformed about their rank in their cohort and that they tend to underestimate their position in the distribution of grades. We randomly assign some students into a treatment that gave them access to information regarding their relative position in the distribution of grades. The treatment was effective in informing students of their rank compared to a control sample who were not given access to this information and who remained relatively uninformed and underestimated their rank. We found that providing feedback on students' relative performance had a negative impact on their performance in terms of the number of exams passed and AGPA. After a short period, however, the treated students catch up in terms of their performance. Moreover, by regularly providing access to this information to the treatment group over the course of their studies, there is no further impact on their performance. In addition to the effect on academic performance, we found a positive effect on self-reported student satisfaction with the quality of the courses. This was perhaps a response to the positive surprise concerning their own ranking. Our results suggest that the impact of relative performance feedback may depend crucially on individuals prior information and their preferences.

Our study highlights a number of important considerations regarding providing students with feedback and raises a number of interesting questions that are relevant to policymakers and education authorities. First, the timing of the information is relevant. We showed that the impact of the treatment is confined to the first time that the students receive the information. If the information had been provided in the final 
year of study, or after graduation, the impact could have been different. This therefore raises the question of the optimal timing of information release, which also interacts with the length of the course. If, for example, the program lasts three or four years, as in the case of an undergraduate degree, the optimal timing might be different than that for an MSc lasting just one year. Second, the reference group might matter. The students in our study compare themselves to the cohort to which they belong, and thus the students' reference group is unchanged over time. This might be one reason for the lack of response to feedback beyond the first time students received information. If the reference group changed, say because at a certain point in time students specialize, or declare majors, then the information may once again have an impact. Third, the coarseness of the information provided may play a role. We provided very detailed information, in particular, students learned about the decile to which they belonged. If students were only informed of whether they were above or below an average student, or if they were given the exact percentile, the response might have been different. Again, there may an optimal information partition to provide (Diamond 1985). Fourth, the incentives associated with relative performance could change the response to the information. In our setting, there was no explicit reward within the university for ranking high versus low; in other words, there was no immediate competition for a better position. Finally, whether information feedback is provided privately or publicly may have significant impact. In our case, it was provided privately. If such a ranking were made public, there might be some consequences because of status seeking, even in the absence of explicit rewards within the university.

\section{References}

[1] Azmat, Ghazala and Nagore Iriberri (2010), "The Importance of Relative Performance Feedback Information: Evidence from a Natural Experiment Using High School Students," Journal of Public Economics, Vol. 94(7-8), pp. 435-452.

[2] Azmat, Ghazala and Nagore Iriberri (2016), "The Provision of Relative Perfor- 
mance Feedback: An Analysis of Performance and Satisfaction," Journal of Economics and Management Strategy 25(1), 77-110.

[3] Barankay, Iwan (2012), "Rank Incentives: Evidence from a Randomized Workplace Experiment", mimeo.

[4] Bedard, Kelly, and Peter Kuhn (2008), "Where class size really matters: Class size and student ratings of instructor effectiveness," Economics of Education Review $27(3), 253-265$.

[5] Blader, Steven, Claudine Madras Gartenberg and Andrea Prat (2015), "The Contingent Effect of Management Practices," Columbia Business School Research Paper No. 15-48.

[6] Blanes i Vidal, Jordi and Mareike Nossol (2011), "Tournaments without Prizes: Evidence from Personnel Records," Management Science Vol. 57, pp. 1721-1736.

[7] Charness, G., Masclet, D., and M.C. Villeval. (2013), "The Dark Side of Competition for Status," Management Science 60(1), 38-55.

[8] Credé, Marcus, Sylvia G. Roch, and Urszula M. Kieszczynka (2010) "Class attendance in college a meta-analytic review of the relationship of class attendance with grades and student characteristics," Review of Educational Research 80, 272-295.

[9] Diamond, Douglas W. (1985), "Optimal release of information by firms," The Journal of Finance 40, 1071-1094.

[10] Emerson, Tisha LN, and Beck A. Taylor (2004), "Comparing student achievement across experimental and lecture-oriented sections of a principles of microeconomics course," Southern Economic Journal (2004), 672-693.

[11] Eriksson, T., Poulsen, A., Villeval, M., (2009), "Feedback and incentives: experimental evidence," Labour Economics 16, 679-688.

[12] Gerhards, L. and N. Siemery, (2014), "Private versus public feedback: The incentive effects of symbolic awards," mimeo. 
[13] Gill, D., Kissova, Z., Lee, J., and V. Prowse, (2016), "First-place loving and last-place loathing: How rank in the distribution of performance affects effort provision," mimeo.

[14] Gok, Tolga (2011), "Comparison of student performance using web-and paperbased homework in large enrollment introductory physics courses," International Journal of the Physical Sciences 6 (2011), 3740-3746.

[15] Hannan, R.L., Krishnan, R., Newman, D., (2008), "The effects of disseminating relative performance feedback in tournament versus individual performance compensation plans," The Accounting Review pp.83-4.

[16] Hoxby, Caroline M. (2009), "The Changing Selectivity of American Colleges," The Journal of Economic Perspectives 23, 95-118.

[17] Katreniakova, Dagmara (2014), "Social Comparison, Rewards and Incentives to Learn: A randomized control trial in Uganda," CERGE-EI, mimeo.

[18] Khunen, Camelia N., and Tymula Agnieszka (2012), "Feedback, Self-Esteem, and Performance in Organizations," Management Science, Vol. 58(1), pp. 94-113.

[19] Kuziemko, I., R. Buell, T. Reich, and M. Norton (2013), "Last-place Aversion: Evidence and Redistributive Implications," Quarterly Journal of Economics (forthcoming).

[20] Moore, Don A., and Daylian M. Cain (2007), "Overconfidence and underconfidence: When and why people underestimate (and overestimate) the competition," Organizational Behavior and Human Decision Processes 103, 197-213.

[21] Sacerdote, Bruce (2001), "Peer Effects with Random Assignment: Results for Dartmouth Roommates," The Quarterly journal of economics, 116(2), 681-704.

[22] Spence, Michael (1973), "Job market signaling," The quarterly journal of Economics 87, 355-374. 
[23] Tran, Anh, and Richard Zeckhauser (2012), "Rank as an inherent incentive: Evidence from a field experiment," Journal of Public Economics, Vol 96, pp. 645-650.

[24] Williams, James, and David Kane (2009), "Assessment and feedback: Institutional experiences of student feedback, 1996 to 2007." Higher Education Quarterly 63: 264-286. 
Figure 1: Assignment to Tutorial and Lecture Groups

Surname initials
\begin{tabular}{|c|}
\hline AA-BZ \\
\hline CA-FEIZ \\
\hline FEJ-GONZAZ \\
\hline GONZB-LIZ \\
\hline LJ-MORZ \\
\hline MOS-POZ \\
\hline PR-SAM \\
\hline SAN-ZZ \\
\hline
\end{tabular}

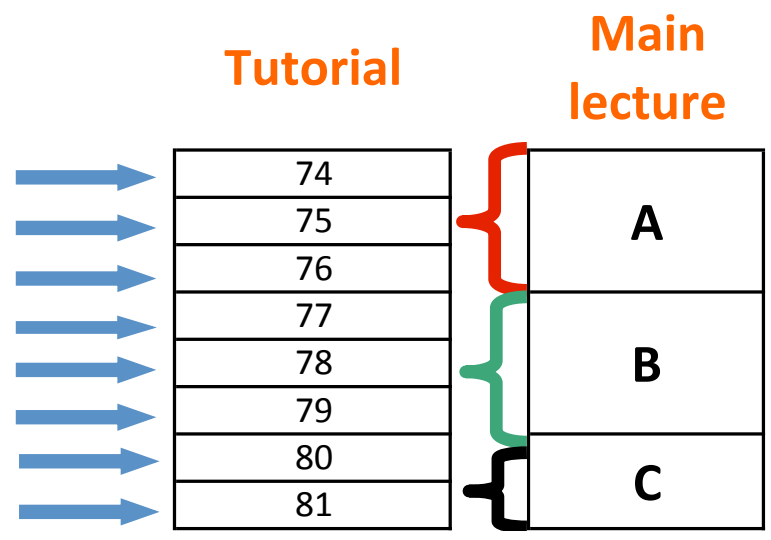

Note: This assignment corresponds to 1st year students, Business Administration, Getafe, Spanish track, 2010.

Figure 2: Feedback on Relative Performance

\section{After logging in....}

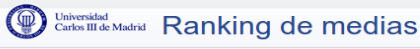

Consulta de posición

Surname, Name

Facultad de Ciencias Sociales y Jurídicas, Grado en Finanzas y Contrabilidad

Media

Créd. Superados 48

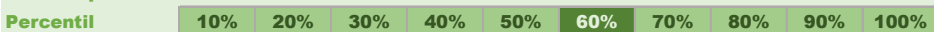


Figure 3: Entry grade and 1st year grades in college

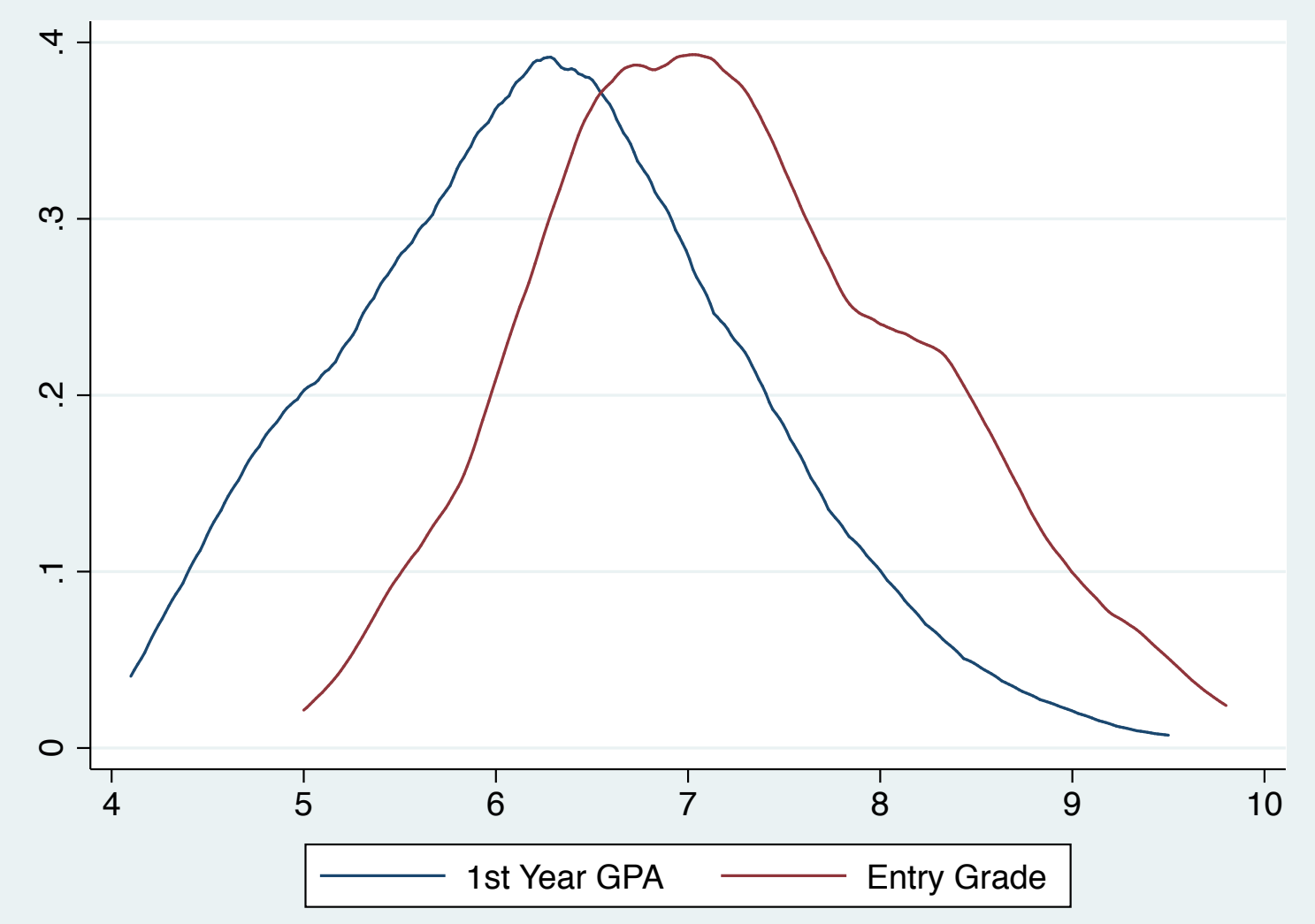


Figure 4: Relative performance at the beginning of the 2nd year

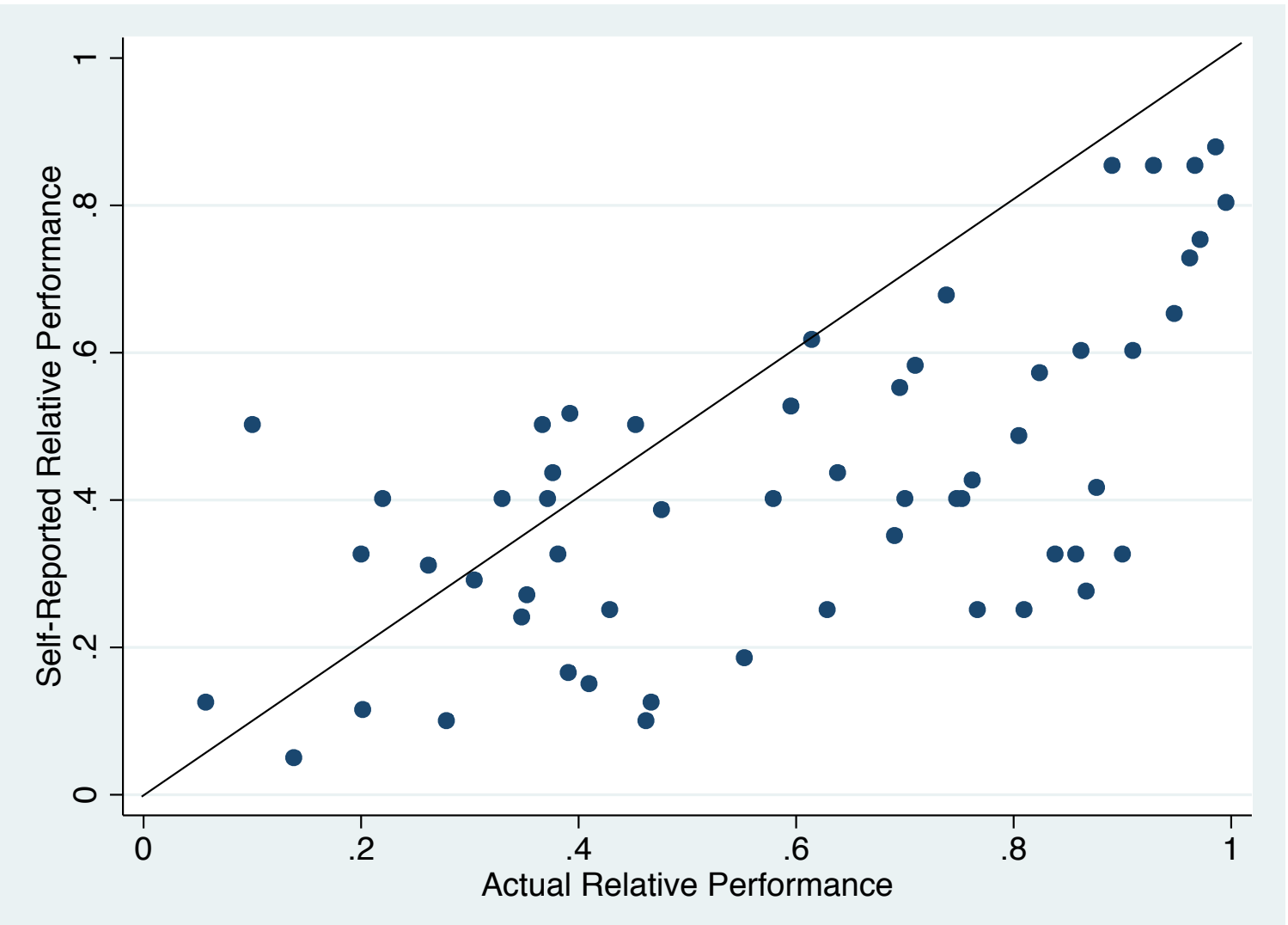

Note: The figure includes information from 57 second year Economics students, class of 2014, who were surveyed in November 2011. The x-axis reports the actual position in the ranking, normalized between 0 (lowest grade) and 1 (highest grade) among students who enrolled in the same degree in Fall 2009. The y-axis provides information on the self-reported relative performance, normalized in a similar way. 
Figure 5: Share of individuals who check the ranking, by quartile

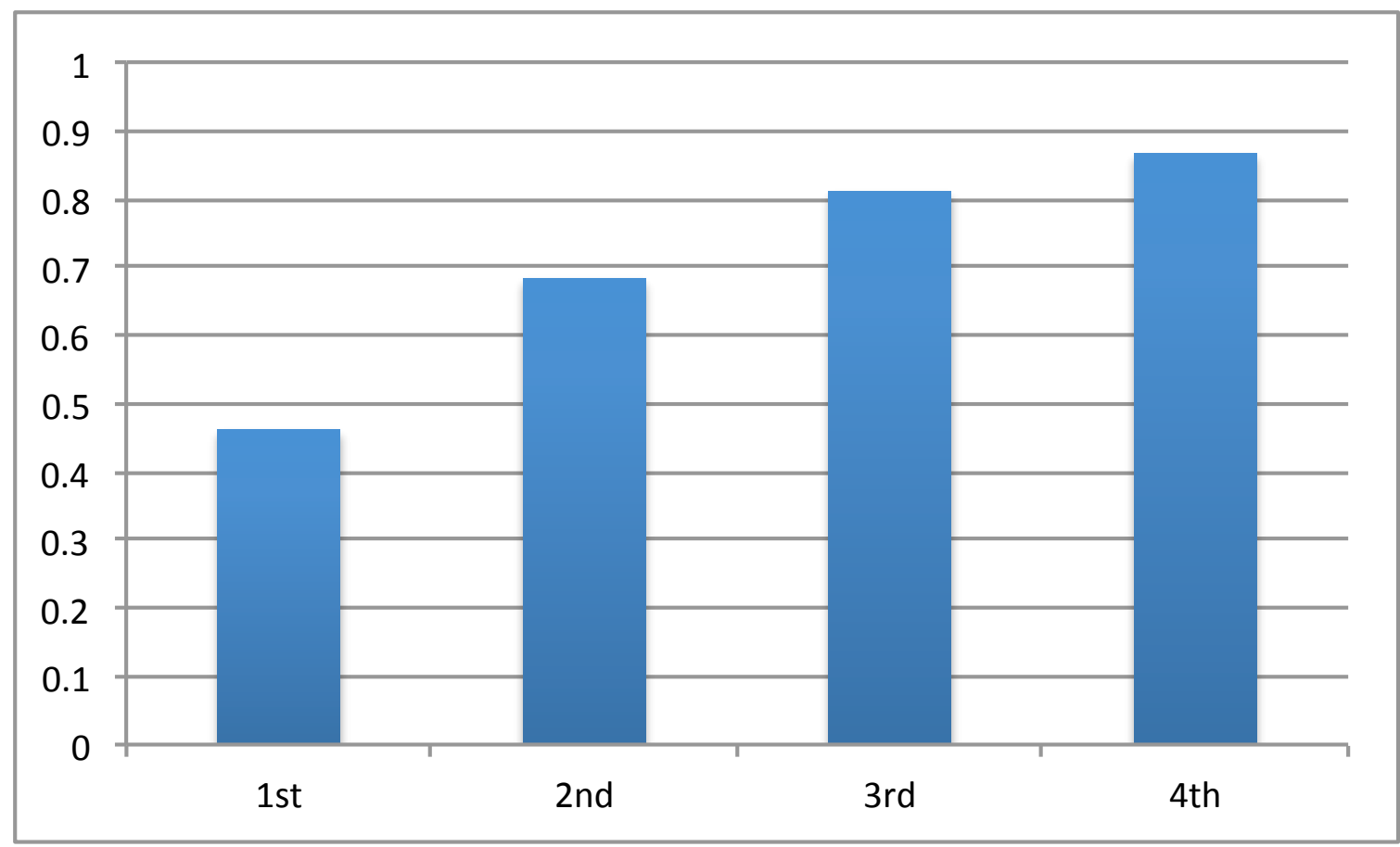

Figure 6: Information over time

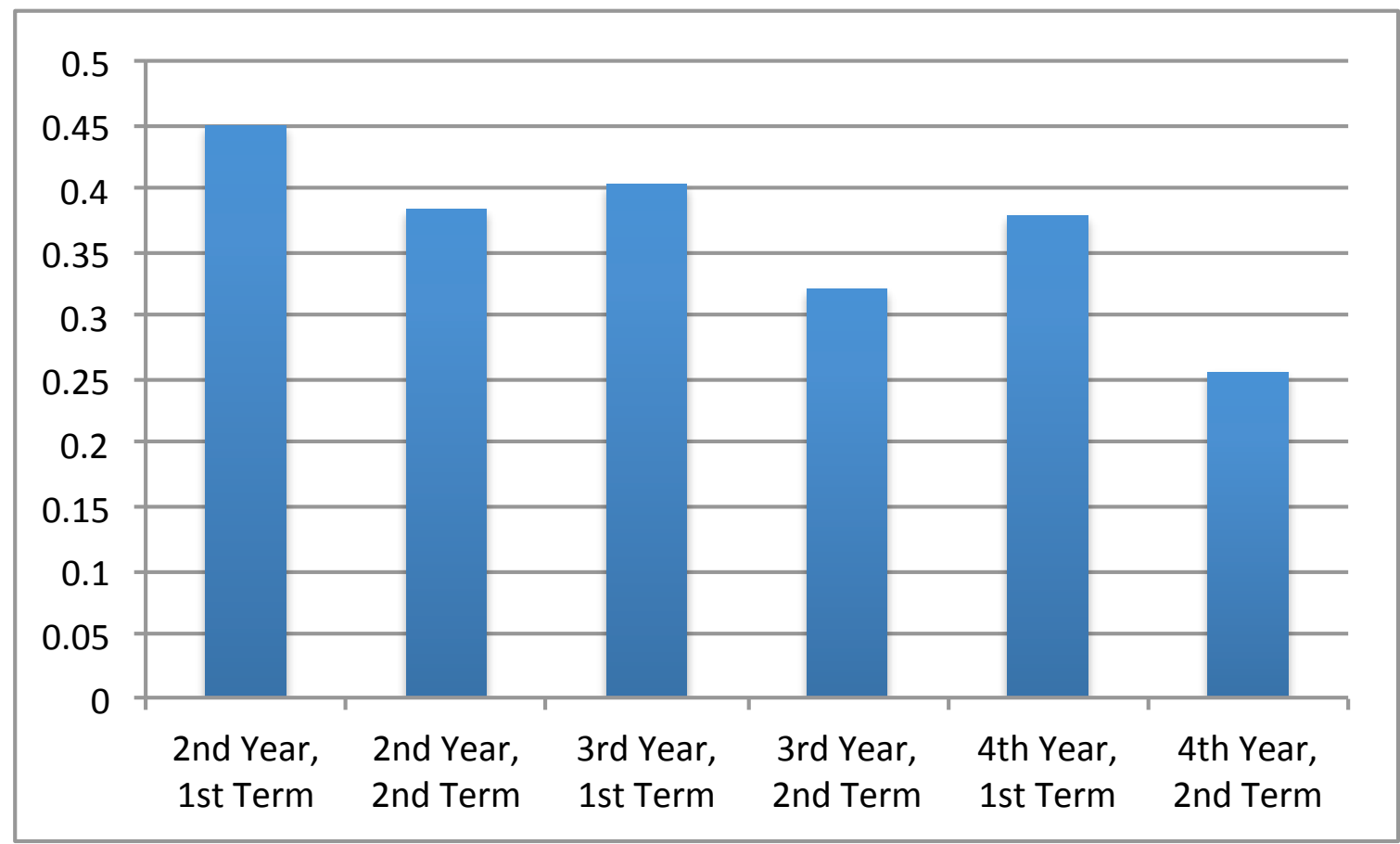

Note: Each bar reflects the proportion of people who experienced mobility from one term to the next in terms of their decile in the relative distribution. For instance, approximately $45 \%$ of individuals were placed in a different decile at the end of the 1st term of their 2nd year relative to their position at the end of the 1st year. 
Figure 7: Relative performance at graduation, treatment group

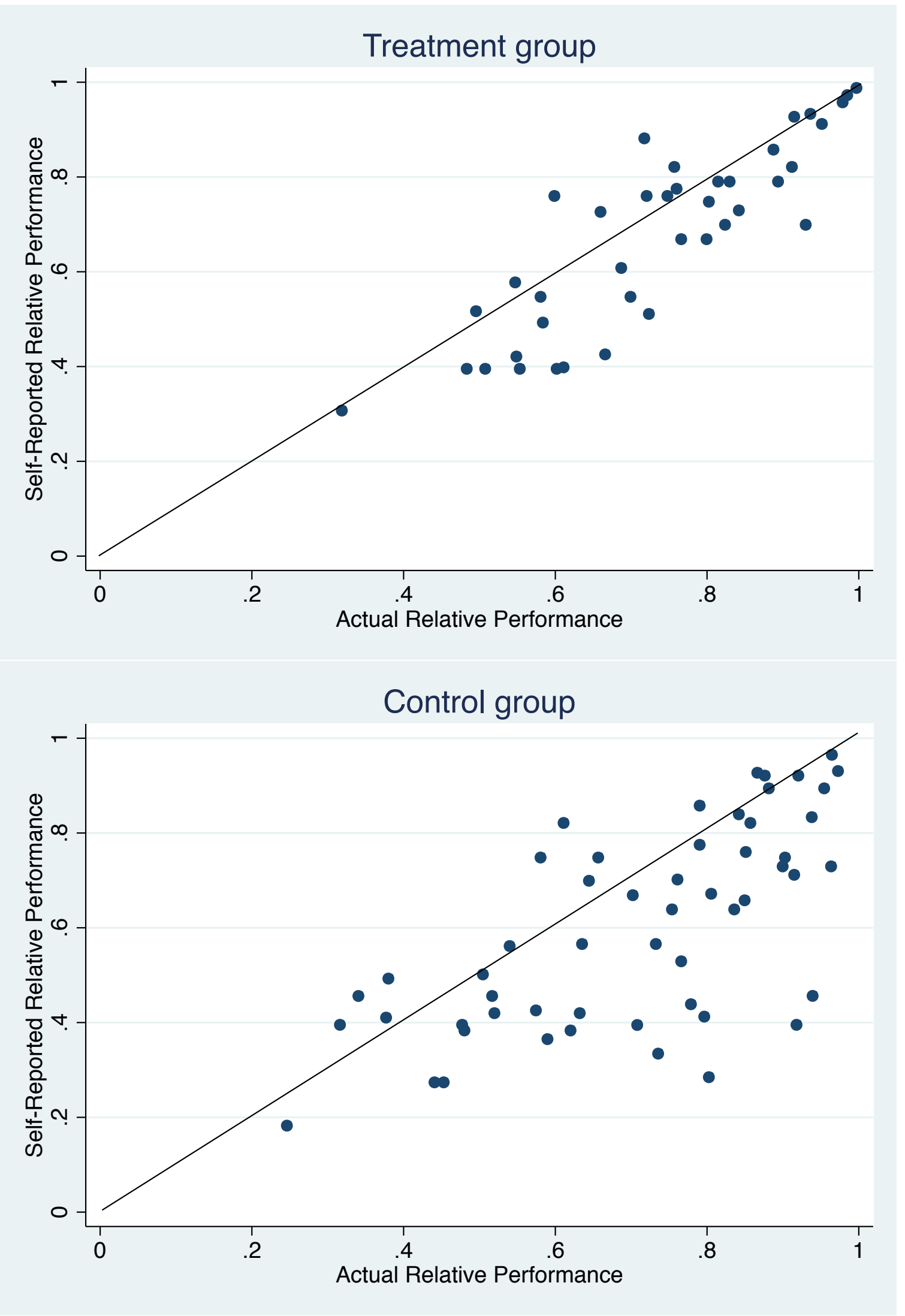

Note: The figure includes information from 93 students in Economics and Business who were surveyed in the summer of 2013, at the time of graduation. The upper (lower) panel includes students in the treatment (control) group. The $\mathrm{x}$-axis reports the actual position in the ranking, normalized between 0 (lowest grade) and 1 (highest grade), relative to students from the same cohort. The y-axis provides information on the self-reported relative performannce. 


\section{Figure 8: Expected \& Actual Relative Performance}

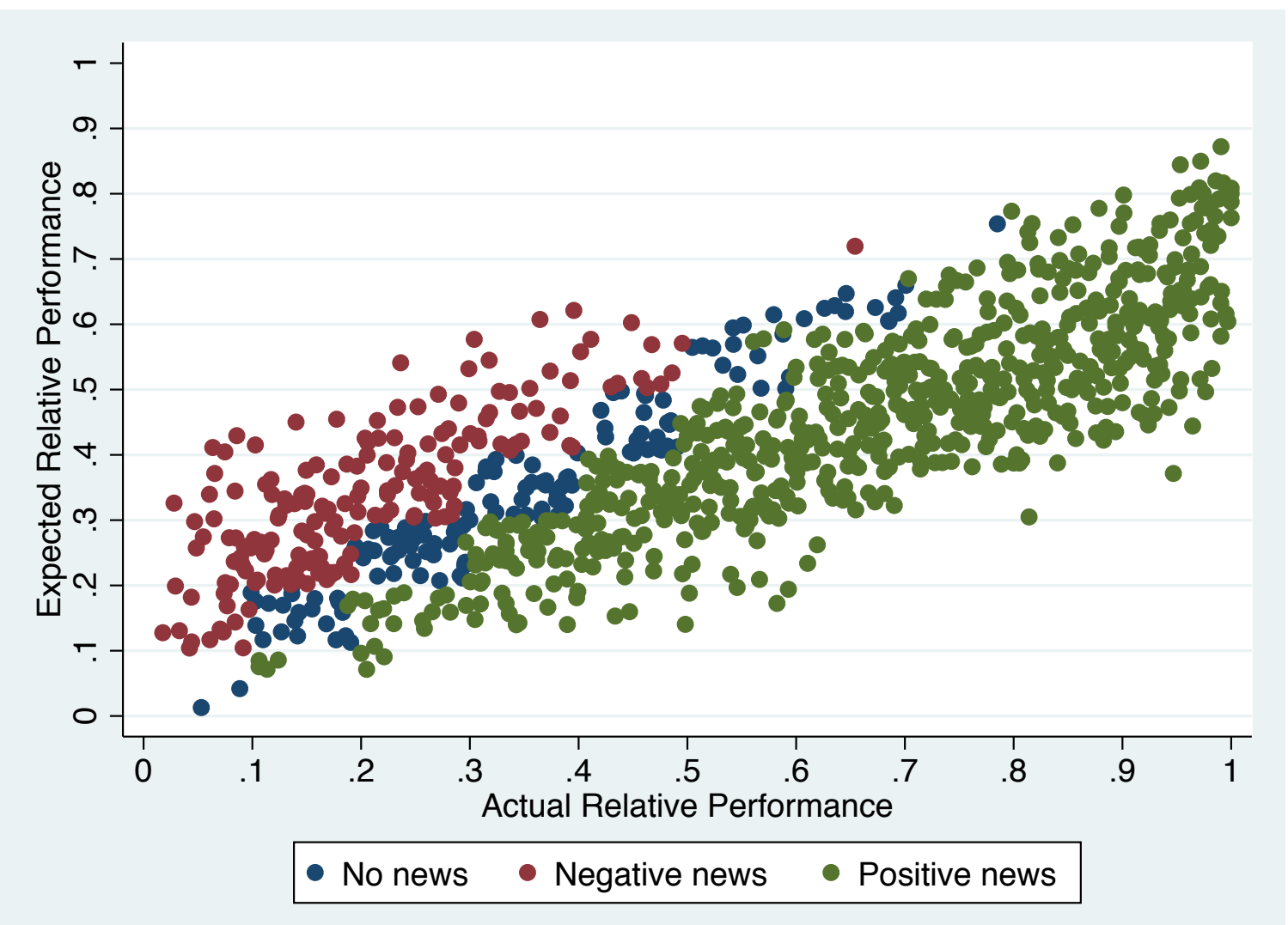

Note: The figure includes information on the actual ranking of the 977 individuals who participated in the intervention and on their expected ranking, according to their observable characteristics. The red group includes individuals who expect a higher ranking than their actual one, the blue group includes individuals with accurate expectations, and the green group includes individuals who are expected to underestimate their relative ranking. 
Table 1: Assignment to the treatment

\begin{tabular}{lccccc}
\hline & \multicolumn{2}{c}{ Southern Campus } & & \multicolumn{2}{c}{ Northern Campus } \\
\cline { 2 - 3 } & Treatment & Control & & Treatment & Control \\
\hline $\begin{array}{l}\text { Finance and Account- } \\
\text { ing }\end{array}$ & $36(1)$ & $59(1)$ & & & \\
Economics & $47(1)$ & $187(2)$ & & & \\
Business & $60(1)$ & $121(2)$ & & $40(1)$ & 35 \\
Law & $60(1)$ & $132(2)$ & & & \\
Law and Business & $50(1)$ & $49(1)$ & & $61(1)$ & $40(1)$ \\
\hline Note: Each cell includes information on the number of students assigned to each group and,
\end{tabular}

in parentheses, on the number of lecture groups.

Table 2: Predetermined descriptive statistics, individual level

\begin{tabular}{lcccc}
\hline & 1 & 2 & 3 & 4 \\
\hline & \multicolumn{3}{c}{ All } & \multicolumn{2}{c}{ Treated-Control } \\
& Mean & St. Dev. & Difference & $p$-value \\
\hline Female & 0.54 & 0.50 & 0.03 & 0.43 \\
Foreigner & 0.03 & 0.18 & -0.00 & 0.71 \\
High School & 0.95 & 0.21 & -0.02 & 0.17 \\
Entry Grade & 7.24 & 0.99 & $-0.10^{*}$ & 0.07 \\
Geographic origin: & & & & \\
Central Madrid & 0.31 & 0.46 & -0.01 & 0.81 \\
Western Madrid & 0.11 & 0.32 & 0.01 & 0.72 \\
Southern Madrid & 0.22 & 0.41 & $0.05^{*}$ & 0.07 \\
Other regions & 0.30 & 0.46 & -0.04 & 0.19 \\
Performance 1st year at university: & & & & \\
Accumulated GPA & 6.02 & 1.36 & -0.05 & 0.45 \\
Percentile & 0.54 & 0.27 & -0.02 & 0.40 \\
Exams taken & 4.89 & 0.78 & -0.06 & 0.23 \\
Exams passed & 3.70 & 1.49 & -0.09 & 0.64 \\
Retakes taken & 2.12 & 2.37 & 0.14 & 0.39 \\
Retakes passed & 0.80 & 0.97 & 0.01 & 0.85 \\
\hline
\end{tabular}

Note: The table includes information on 977 students that took part in the intervention, except variable Entry Grade which is available only for 966 students. Column (3) reports the difference between the treatment and the control group, conditional on degree. Column (3) reports the p-value of this difference. Accumulated GPA and Percentile are measured at the end of the first year. Exams taken and Exams passed provide information for the second term of the first year. 
Table 3: Teaching evaluations

\begin{tabular}{lccccc}
\hline & 1 & 2 & & 3 & 4 \\
\hline & \multicolumn{2}{c}{ All } & & Treated-Control \\
\cline { 2 - 3 } \cline { 5 - 6 } & Mean & St. Dev. & & Difference & $p$-value \\
\hline \multirow{3}{*}{ Satisfaction } & 3.87 & 0.76 & & 0.01 & 0.89 \\
Hours of study & 2.92 & 0.45 & & 0.13 & 0.13 \\
Grading & 3.56 & 0.67 & & 0.00 & 0.99 \\
\hline \multirow{3}{*}{ Satisfaction } & 3.63 & 0.85 & $0.30^{* * *}$ & 0.01 \\
Hours of study & 3.00 & 0.48 & & 0.15 & 0.13 \\
Grading & 3.15 & 0.82 & & 0.12 & 0.34 \\
\hline
\end{tabular}

Note: The upper panel includes information from 182 tutorial groups who completed their teaching evaluations in Fall of academic year 20102011 , before the intervention took place. The lower panel provides information from 165 tutorial groups who completed their teaching evaluations in Spring of academic year 2010-2011, after the beginning of the intervention. In each panel, the first row provides information on students' self-reported satisfaction with the overall quality of each course, coded in a scale from 1 (not at all) to 5 (very satisfied). The second row reports the average satisfaction with the grading, also coded in a scale from 1 (not at all) to 5 (very satisfied). The third row provides information on the number of hours studied weekly. Hours of study takes value 1 if the individual studied less than an hour per week; 2, between one and four hours; 3 , four to seven hours; 4 , seven to ten hours and 5 more than ten hours.

Table 4: Prior information on relative rank - 2nd year survey

\begin{tabular}{lcc}
\hline Dep. var.: Self-reported - Actual Rank & 1 & 2 \\
\hline Female & $-0.09^{*}$ & -0.07 \\
& $(0.05)$ & $(0.04)$ \\
True rank & & $-0.66^{* * *}$ \\
& & $(0.11)$ \\
Entry grade & & $0.11^{* * *}$ \\
Constant & $-0.12^{* * *}$ & $-0.039^{* *}$ \\
& $(0.03)$ & $(0.21)$ \\
Adj. R-squared & 0.04 & 0.50 \\
$\mathrm{~N}$ & 57 & 52 \\
\hline
\end{tabular}


Table 5: Who checks the information?

\begin{tabular}{lcc}
\hline & 1 & 2 \\
\hline Female & $0.106^{* *}$ & $0.079^{*}$ \\
True rank & {$[0.047]$} & $(0.045)$ \\
& & $0.585^{* * *}$ \\
Entry grade & & $(0.097)$ \\
& & -0.047 \\
Constant & $0.665^{* * *}$ & $(0.034)$ \\
& {$[0.034]$} & $(0.229)$ \\
Observations & & \\
R-squared & 354 & 347 \\
\hline
\end{tabular}

Note: The regression includes information from 354 students who were assigned to the treatment group. The dependent variable is a dummy that takes value one if the students checked at least once the information. Robust standard errors in parenthesis. ${ }^{*}: \mathrm{p}<0.10,{ }^{* *} \mathrm{p}<0.05,{ }^{* * *} \mathrm{p}<0.01$

Table 6: Available information at graduation

\begin{tabular}{lcc}
\hline & 1 & 2 \\
\hline Treatment & $-0.050^{* *}$ & $-0.048^{*}$ \\
Female & $(0.025)$ & $(0.025)$ \\
& & $0.048^{* *}$ \\
True rank & & $(0.022)$ \\
Entry grade & 0.023 \\
Constant & & $(0.070)$ \\
& $0.143^{* * *}$ & -0.004 \\
Adj. R-squared & $(0.019)$ & $0.023)$ \\
$\mathrm{N}$ & & 0.129 \\
\end{tabular}

Note: The regression includes information from 93 students who were surveyed at graduation. The dependent variable is the difference between the self-reported position in the ranking and the actual one, normalized between 0 and 1 . Robust standard errors in parenthesis. ${ }^{*}: \mathrm{p}<0.10,{ }^{* *} \mathrm{p}<0.05,{ }^{* * *} \mathrm{p}<0.01$ 
Table 7: Impact on academic performance - Intention-to-treat effect

\begin{tabular}{|c|c|c|c|c|c|c|}
\hline & 1 & 2 & 3 & 4 & 5 & 6 \\
\hline \multirow[b]{3}{*}{ Dependent variable: } & \multicolumn{2}{|r|}{ All } & \multicolumn{4}{|c|}{ Treated-Control } \\
\hline & \multirow[b]{2}{*}{ Mean } & \multirow[b]{2}{*}{ St. Dev. } & \multirow{2}{*}{\multicolumn{2}{|c|}{$\begin{array}{l}\text { Without controls } \\
\text { Difference St. Error }\end{array}$}} & \multicolumn{2}{|c|}{ With controls } \\
\hline & & & & & Difference & St. Error \\
\hline & \multicolumn{6}{|c|}{ Second year } \\
\hline Exams taken & 10.69 & 3.19 & -0.06 & $(0.17)$ & -0.05 & $(0.14)$ \\
\hline Exams passed & 7.75 & 3.83 & $-0.50^{* *}$ & $(0.21)$ & $-0.36^{* *}$ & $(0.18)$ \\
\hline Retakes taken & 2.91 & 2.94 & $0.47^{*}$ & $(0.27)$ & 0.34 & $(0.22)$ \\
\hline \multirow[t]{2}{*}{ Retakes passed } & 1.12 & 1.25 & $0.23^{*}$ & $(0.12)$ & $0.19^{*}$ & $(0.11)$ \\
\hline & \multicolumn{6}{|c|}{ Third year } \\
\hline Exams taken & 10.26 & 4.52 & 0.12 & $(0.31)$ & 0.25 & $(0.27)$ \\
\hline Exams passed & 8.07 & 4.06 & -0.03 & $(0.27)$ & 0.13 & $(0.24)$ \\
\hline Retakes taken & 2.15 & 2.65 & 0.10 & $(0.16)$ & 0.06 & $(0.17)$ \\
\hline \multirow[t]{2}{*}{ Retakes passed } & 0.98 & 1.28 & 0.07 & $(0.08)$ & 0.05 & $(0.09)$ \\
\hline & \multicolumn{6}{|c|}{ Fourth year } \\
\hline Exams taken & 8.59 & 4.68 & 0.06 & $(0.36)$ & 0.16 & $(0.32)$ \\
\hline Exams passed & 6.69 & 4.41 & 0.22 & $(0.33)$ & 0.27 & $(0.31)$ \\
\hline Retakes taken & 1.22 & 2.09 & -0.16 & $(0.17)$ & -0.17 & $(0.18)$ \\
\hline \multirow[t]{2}{*}{ Retakes passed } & 0.68 & 1.11 & 0.02 & $(0.07)$ & 0.02 & $(0.07)$ \\
\hline & \multicolumn{6}{|c|}{ Overall } \\
\hline All exams taken & 36.46 & 13.91 & 0.41 & (1.04) & 0.49 & $(0.94)$ \\
\hline All exams passed & 25.82 & 11.54 & 0.01 & $(0.71)$ & 0.32 & $(0.70)$ \\
\hline Dropout & 0.15 & 0.36 & 0.00 & $(0.03)$ & -0.01 & $(0.02)$ \\
\hline Graduation in 4 years & 0.51 & 0.5 & -0.01 & $(0.03)$ & 0.02 & $(0.03)$ \\
\hline Final AGPA & 6.30 & 1.27 & -0.07 & $(0.10)$ & -0.03 & $(0.06)$ \\
\hline Grading elective courses & 0 & 1 & 0.03 & $(0.03)$ & 0.03 & $(0.03)$ \\
\hline
\end{tabular}

Note: Columns 1 and 2 include information on 977 students that took part in the intervention, except for the variable graduation rate, which excludes 200 students enrolled in the six-years degree in Business and Law. The variables Exams taken and Exams passed refer respectively to the number of exams taken or passed during the regular exam season (January and May). Variables Retakes taken and Retakes passed refer exams taken and passed during the retake season (June). The lower panel provides information measured at the end of the fourth academic year. AGPA refers to the Accumulated Grade Point Average. Grading elective courses is a measure of the grades that students obtained in the previous two years in the elective courses selected by the students. Column 3 reports the main estimates from equation (9), and each row corresponds to a different regression where the independent variable is a dummy that takes value one if the student was part of the treatment group and the dependent variable is indicated in column 1. For instance, the first cell in column 3 indicated that treated students enrolled in 0.06 fewer courses that comparable students in the same degree. In columns 5 regressions also include controls for a set of individual predetermined characteristics. Columns 4 and 6 report standard errors clustered at the tutorial level in parenthesis. ${ }^{*}: \mathrm{p}<0.10,{ }^{* *} \mathrm{p}<0.05,{ }^{* * *} \mathrm{p}<0.01$. 
Table 8: Impact on academic performance - IV estimates

\begin{tabular}{lccccc}
\hline & 1 & 2 & & 3 & 4 \\
\hline & \multicolumn{2}{c}{ Regular exams } & & \multicolumn{2}{c}{ Retakes } \\
\cline { 2 - 3 } \cline { 5 - 6 } & Taken & Passed & & Taken & Passed \\
\cline { 1 - 2 } Second year & -0.074 & $-0.493^{* *}$ & & 0.465 & $0.255^{*}$ \\
& $(0.186)$ & $(0.244)$ & & $(0.301)$ & $(0.150)$ \\
\hline Third year & 0.347 & 0.183 & & 0.082 & 0.066 \\
& $(0.374)$ & $(0.331)$ & & $(0.235)$ & $(0.120)$ \\
\hline Fourth year & 0.216 & 0.373 & & -0.239 & 0.027 \\
& $(0.433)$ & $(0.423)$ & & $(0.243)$ & $(0.089)$ \\
\hline \hline
\end{tabular}

Note: Each cell reports the result of a different IV regression on the sample of 966 students that took part in the intervention and for whom there is information available on their predetermined characteristics. The independent variable is a dummy variable that takes value one if the student accessed the information on relative performance, instrumented by being assigned to the treatment. The first two rows provide information for the 2nd academic year, the second two rows for the 3rd academic year, and the last two rows for the fourth academic year. The first two columns report information from exams taken during the regular period (January and May). Columns (3) and (4) provide information from retakes (June). The dependent variable in columns (1) and (3) is the number of exams taken. The dependent variable in columns (2) and (4) is the number of exams passes. All regressions include a control for academic performance during the first year and degree fixed effects. Standard errors clustered at the tutorial level in parenthesis. ${ }^{*}: \mathrm{p}<0.10,{ }^{* *} \mathrm{p}<0.05,{ }^{* * *}$ $\mathrm{p}<0.01$.

Table 9: Heterogeneity analysis

\begin{tabular}{|c|c|c|c|c|c|c|c|c|c|c|}
\hline \multirow[b]{3}{*}{ Sample: } & \multirow[t]{2}{*}{1} & 2 & 3 & 4 & 5 & 6 & 7 & 8 & 10 & \\
\hline & & \multicolumn{3}{|c|}{ News } & \multicolumn{2}{|c|}{ Gender } & \multicolumn{2}{|c|}{ 1st year grades } & \multicolumn{2}{|c|}{ HS grades } \\
\hline & All & Positive & No News & Negative & Female & Male & Low & High & Low & High \\
\hline Treatment & $\begin{array}{c}-0.361^{* *} \\
(0.176)\end{array}$ & $\begin{array}{c}-0.470^{* *} \\
(0.216)\end{array}$ & $\begin{array}{c}0.164 \\
(0.483)\end{array}$ & $\begin{array}{c}0.257 \\
(0.497)\end{array}$ & $\begin{array}{r}-0.464^{*} \\
(0.263)\end{array}$ & $\begin{array}{l}-0.179 \\
(0.247)\end{array}$ & $\begin{array}{l}-0.331 \\
(0.286)\end{array}$ & $\begin{array}{l}-0.183 \\
(0.199)\end{array}$ & $\begin{array}{c}-0.604^{* *} \\
(0.272)\end{array}$ & $\begin{array}{l}-0.128 \\
(0.243)\end{array}$ \\
\hline $\begin{array}{l}\text { Adj. R-squared } \\
\mathrm{N}\end{array}$ & $\begin{array}{c}0.634 \\
966\end{array}$ & $\begin{array}{c}0.687 \\
644\end{array}$ & $\begin{array}{c}0.613 \\
142\end{array}$ & $\begin{array}{c}0.588 \\
180\end{array}$ & $\begin{array}{c}0.613 \\
521\end{array}$ & $\begin{array}{c}0.640 \\
445\end{array}$ & $\begin{array}{c}0.541 \\
435\end{array}$ & $\begin{array}{c}0.709 \\
531\end{array}$ & $\begin{array}{c}0.569 \\
482\end{array}$ & $\begin{array}{c}0.640 \\
479\end{array}$ \\
\hline
\end{tabular}


Appendix A: Tables

Table A1: Expected rank - 2nd year survey

\begin{tabular}{lc}
\hline Dep. var.: Self-reported rank & 1 \\
\hline & \\
Female & -0.07 \\
& $(0.04)$ \\
True rank & $0.34^{* * *}$ \\
& $(0.11)$ \\
Entry grade & $0.11^{* * *}$ \\
& $(0.03)$ \\
Constant & $-0.49^{* *}$ \\
& $(0.21)$ \\
Adj. R-squared & 0.48 \\
$\mathrm{~N}$ & 52 \\
\hline
\end{tabular}

